REVIEW

\title{
No Hypertensive Disorder of Pregnancy; No Preeclampsia-eclampsia; No Gestational Hypertension; No Hellp Syndrome. Vascular Disorder of Pregnancy Speaks for All
}

\section{Yifru Berhan}

\begin{abstract}
Hypertensive disorders complicate 5\%-10\% of pregnancies with increasing incidence mainly due to upward trends in obesity globally. In the last century, several terminologies have been introduced to describe the spectrum of this disease. The current and widely used classification of hypertensive pregnancy disorders was introduced in 1972 and in 1982, but has not been free of controversy and confusion. Unlike other diseases, the existing terminology combines signs and symptoms, but does not describe the underlying pathology of the disease itself. In this commentary, a detailed account is given to vascular disorder of pregnancy (VDP) as an inclusive terminology taking into account the underlying pathology of the disease on affected organs and systems. A simple and uniform classification scheme for VDP is proposed.
\end{abstract}

KEYWORDS: Gestational hypertension, HELLP syndrome, Hypertensive disorder of pregnancy, Preeclampsia-eclampsia, Vascular disorder of pregnancy

DOI: http://dx.doi.org/10.4314/ejhs.v26i2.12

\section{INTRODUCTION}

Although the occurrence of convulsion in pregnant women was noted around $2200 \mathrm{BC}$, the word eclampsia was first used in 1619. In 1843, the association of convulsion with edema and proteinuria was noted. In 1897, hypertension was detected in pregnant women. In 1900s, taking into account the earlier manifestations of eclampsia, the word preeclampsia was considered during prenatal care (1).

Although the exact mechanism regarding the induction of this disease remains enigmatic, vascular disorder characterized by generalized endothelial damage and vasospasm is a wellknown pathology resulting in systemic complications during pregnancy (2-4). Apart from the pathogenesis, there is also uncertainty in its natural course, diagnosis and screening methods (3). As a result, different experts in the field have given this spectrum of disease different names at different times: nephrotic toxemia, hypertensive toxemia, eclampsia, gestosis, pregnancy induced hypertension, preeclampsia-eclampsia and hypertensive disorders of pregnancy (1). Some authors also classified it as atypical when the course of the disease is eccentric (development of advanced complications without evidences of preeclampsia) (5). The American College of Obstetricians and Gynecologists (ACOG) 2013 guidelines has also classified preeclampsia as with and without severe features (6). Detailed description about the proposed pathogenesis of this disease and its clinical manifestations are beyond the scope of this manuscript.

Neither hypertensive pregnancy disorders nor the current sub-classifications (chronic hypertension, preeclampsia-eclampsia, gestational hypertension, superimposed preeclampsia on chronic hypertension) is inclusive as these terminologies only partly describe the disease's clinical manifestations. Since endothelial damage is the unifying pathology behind all the clinical manifestations (2-4), vascular disorder of

${ }^{1}$ Addis Ababa University, College of medicine and health sciences, Ethiopia

Corresponding Author: Yifru Berhan, Email: yifrub@yahoo.com/yifruberhanm@gmail.com 
pregnancy (VDP) is a simplified but comprehensive terminology to describe the spectrum of the disease. Although the timing of occurrence varies, all the systemic complications (cardiovascular, renal, hematologic, intracranial, hepatic, pulmonary and uteroplacental) are the consequences of the generalized endothelial vascular damage resulting in vasospasm. Other authors also noted that endothelial damage is considered central to the multiple-organ pathophysiology of this disease (7).
As schematically presented in Figure 1, in the natural course of this disease, the endothelial damage and the vasospasm are the 'engine' and 'steering wheel,' respectively. The early maximum effect in any organ or system will result in the earliest clinical manifestation. The most commonly observed and earliest manifestations are hypertension and proteinuria. They have been used as a baseline diagnostic criteria for preeclampsia for the past century until the most recent ACOG revision, which eliminates proteinuria as a must for diagnosis (6).

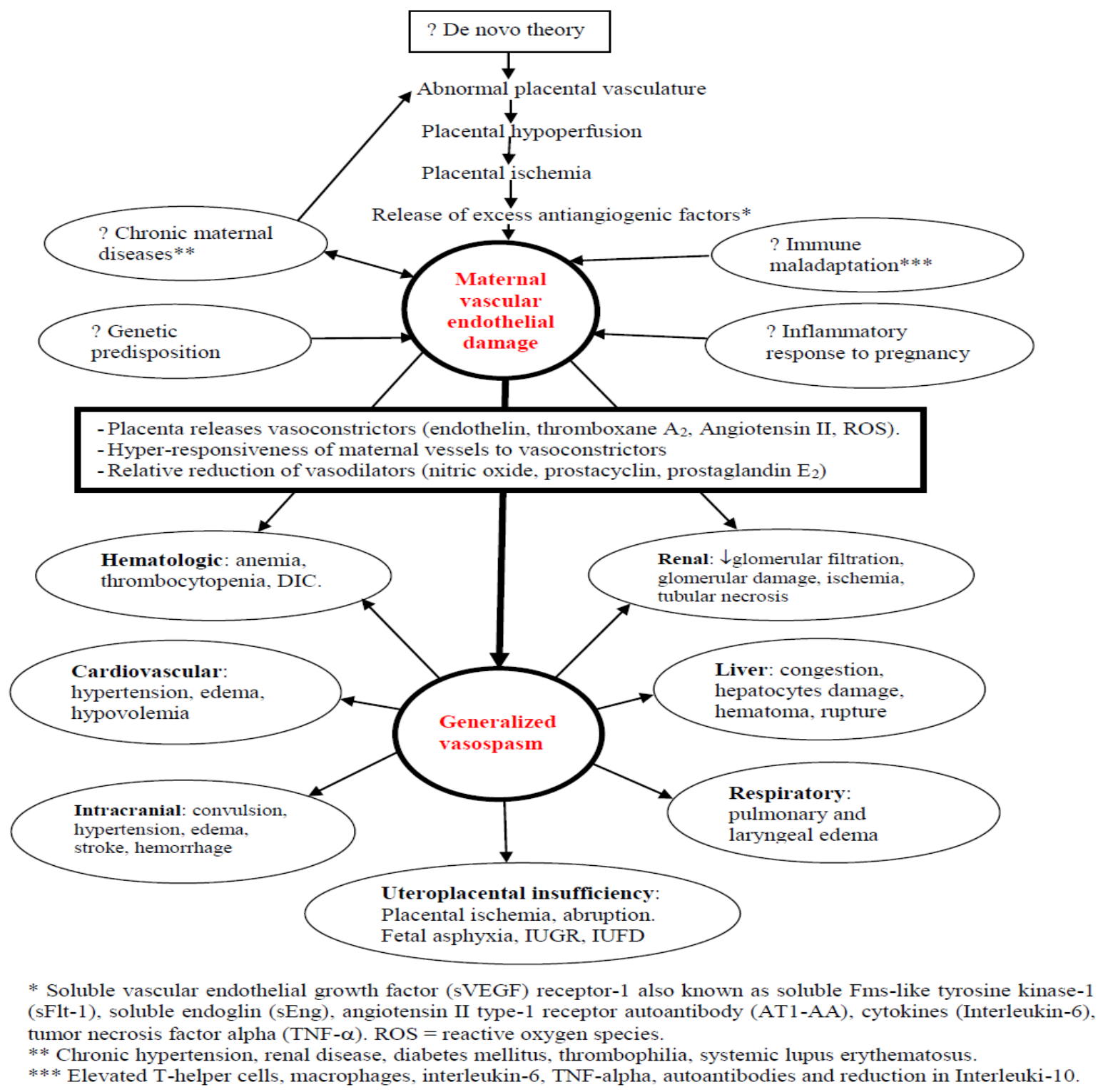

Figure 1: Schematic representation of theories leading to maternal vascular endothelial damage and vasospasm; vasospasm in turn leading to systemic manifestations 
Vasospasm and resulting intravascular dehydration (hypovolemia) have the potential to effect any organ or system at any stage of the disease. The development of convulsion before hypertension, presentation with hematologic and hepatic abnormalities in normotensive women, and the occurrence of late postpartum eclampsia (up to 4 weeks postpartum) is evidence for the importance of the vascular disorder and the unpredictable course of this disease (8-11). The most common severe symptoms (headache, blurred vision, epigastric pain and vomiting) also manifest very haphazardly (8), likely due to underlying susceptibility and individual variation in the effect of the vascular disorder on certain organs.

There is also evidence of the importance of the vascular disorder on disease susceptibility in later life. The vascular disorder during pregnancy was reported as strongly associated with later-life cardiovascular diseases (hypertension, ischemic heart disease, myocardial infarction) $(6,12,13)$. Interestingly, both the cardiovascular disease and preeclampsia share common risk factors (endothelial damage, obesity, hypertension, hyperglycemia, insulin resistance, dyslipidemia) (13). Other investigators have reported an increased long-term risk of death due to cardiovascular disease in women who were diagnosed to have pre-eclampsia and gestational hypertension (14). Others also considered preeclampsia as a 'life-long disorder' (15). The finding of endothelial damage in both preeclampsia and metabolic syndrome and the increased risk of developing preeclampsia among women with metabolic syndrome and vice versa (16) lends evidence to the importance of this vascular disorder on this disease process. Some investigators noted the possibility of metabolic syndrome as an underlying mechanism common to cardiovascular disease and preeclampsia (13). The prominence of the vascular disorder was also observed in the association of later chronic hypertension and cardiovascular morbidity/mortality with early onset and recurrent preeclampsia (13). Unlike preeclampsia, which is characterized by endothelial damage of unknown mechanism, metabolic syndrome stresses the endothelium mechanically and biochemically to result in the dysfunction $(17,18)$.
As pregnancy is known to be diabetogenic, it may also be vasculopathic. More than a quarter of pregnant women diagnosed to have gestational diabetes are likely to have type II diabetes in less than twenty years (19). Similarly, women diagnosed to have preeclampsia are at increased risk of developing cardiovascular disease later in life. Pregnancy may have an amplifying potential to unmask latent chronic medical disorders destined to manifest in later life.

The importance of vasospasm for the occurrence of systemic complication has also been noted indirectly. Although the mechanism is not completely understood, magnesium sulfate has become first-line therapy in preventing occurrence of convulsion because of its effect on cerebral and peripheral vasodilatation, which is an advantage to reduce the vasospasm, ischemia and hypertension found in these disorders $(20,21)$. A randomized clinical trial has also shown a significant increase in fetal umbilical artery and middle cerebral artery blood flow in women treated with magnesium sulfate (22).

Some systemic complications occur late in the disease process but may appear early and present a puzzle for clinicians. For example, eclampsia and HELLP syndrome (hemolytic anemia, elevated liver enzymes, low platelet count) $(4,8)$ are expected to occur in advanced disease but can appear first. In other cases, the first disease manifestation may be hypertension, renal dysfunction, hematologic abnormalities, increased intracranial pressure or hepatic disorder. One systemic complication does not always progress logically after another.

The most important determinant of the clinical manifestation of this disease is the severity of the vascular disorder on any particular organ or system. Other authors also pointed out that the onset of symptoms and signs of this disease may be dictated by the degree and time course of the endothelial damage (23). The association of early onset preeclampsia with persistent endothelial damage was also demonstrated (24). Although multiple pathways have been proposed, the exact etiology of the endothelial damage is not yet known (25). What has been clearly described is first the primary pathology, vascular disorder, followed by secondary pathology, systemic complications with variable time course of onset. 
Stekkinger and colleague from the Netherlands first proposed VDP as an alternate expression for preeclampsia (26). Since the vascular disorder plays a pivotal role central to the disease process in all maternal and fetal complications, and none of the current terminology is inclusive of the whole disease picture, VDP represents the most appropriate terminology until such time as the underlying etiology is certainly identified. Since VDP is a syndrome with a multisystem manifestation, we should avoid the use of jargons of names given by combining two or more clinical manifestations of VDP: hypertension with proteinuria (preeclampsia); anemia, hepatic dysfunction and thrombocytopenia (HELLP syndrome); Partial HELLP syndrome any two of the three present; hypertension with proteinuria and convulsion (eclampsia); isolated hypertension (gestational hypertension); and worsening chronic hypertension (superimposed preeclampsia). Further description is presented to show how inconclusive the existing terminologies are.

Hypertensive disorder of pregnancy is not accurate or inclusive since the disease process can present in the absence of hypertension:

In this disease, hypertension is only one postential manifestation of the vascular disorder. The hypertension is thought to be due to the generalized vasospasm. In previous literature, hypertension has been considered as the hallmark for the diagnosis of preeclampsia-eclampsia (4,6,26). The 2013 ACOG guidelines also maintain hypertension to diagnose preeclampsia (6). There are also few authors who still use the term pregnancy induced hypertension probably to show the association of this disease with hypertension $(27,28)$. If this disease manifests with only hypertension in the second half of pregnancy, gestational hypertension is defined (6). However, what is in common with both preeclampsia-eclampsia and gestational hypertension is the vasospasm or vascular stiffness, which shows improvement with antihypertensive drugs (29).

Several recent investigations on this disease pathogenesis also showed that preeclampsia is not primarily a hypertensive disease (25,28,30-33). There are several circulating markers of endothelial cell injury (endothelin, cellular fibronectin and plasminogen activator inhibitor-1) being found elevated before women became hypertensive and symptomatic for preeclampsia $(34,35)$.

Thus, hypertension is one of the secondary effects of the disease, developing after the vasospastic effect of the disease is severe enough. Interestingly, in clinical practice, hypertension is not always present first or second in the disease process. The effect of the vascular disorder in other systems or organs may manifest earlier than the hypertension. As a result, it is not unusual to encounter preeclamptic women with severe features but still normotensive. In some cases, the severe features of the disease like HELLP syndrome, hepatic subcapsular hematoma and eclampsia can also occur while the blood pressure is in the normal range $(4,8,9,36)$. Since this disease is not always manifesting with hypertension, the phrase "hypertensive disorder" is not inclusive. Therefore, the author's opinion is that this disease should not be tagged with "hypertensive disorder", in which hypertension is one of: 1) the relatively late phenomena appearing when the vasospasm is severe enough; and 2) the signs of the disease but not MUST to make a diagnosis of this disorder.

Eclampsia is not predictably preceded by preeclampsia and can occur in isolation, so this terminology is inadequate at best:

As described above, eclamptic women exhibit a wide spectrum of signs, ranging from severe hypertension and significant proteinuria to absent or minimal hypertension and no proteinuria. The classical course of illness (characterized by a progressive edema, mild to severe hypertension and the onset of severe symptoms, which is followed by the occurrence of convulsion or coma) may not be seen in several women $(5,8,9)$. Specifically, large data including a series of eclamptic women from the United States and Europe showed that about $20 \%$ of eclamptic women did not have any premonitory signs or symptoms before the onset of convulsions $(9,37$ 39). Another large systematic review of eclamptic women also indicated that about a quarter of women were normotensive and symptom free (8). Interestingly, retrospective studies from high income countries also showed that about $50 \%$ of convulsions with no signs and symptoms occurred 
while the women were in the hospital under close supervision $(9,38,39)$.

These findings imply that eclampsia is not always after signs and symptoms of preeclampsia and the appropriateness of the term preeclampsia is thus questionable. In other words, eclampsia is not always the natural linear evolvement of preeclampsia as theorized before (40). The argument is that convulsion or coma (eclampsia) is one of the severe signs of the disease. Convulsion or coma indicates the severity of the effect of the acute endovascular injury on the cerebrum-not necessarily a continuum of the severe preeclampsia.

Pregnant women with acute endovascular injury may first manifest with convulsion, if the effect of the vasospasm is less in other organs and tissues, but more in the cerebrum. As a result, the signs and symptoms preceding the development of eclampsia are nonspecific and their presence may be taken as a marker of end-organ dysfunction and disease severity. If that is the case; rather than giving a separate terminology (eclampsia), which is not always after preeclampsia, why do not we omit this terminology and describe this disease (VDP) by its symptoms (convulsion or coma)?

The existence of HELLP syndrome as a separate disease entity is debatable:

Although Louis Weinstein regarded HELLP syndrome as a separate disease from severe preeclampsia in 1982, many clinicians view it as an entity of preeclampsia (41-43). The HELLP syndrome was also reported as occurring simultaneously with preeclampsia (42) and after the onset of signs and symptoms of preeclampsia $(41,42)$. HELLP syndrome has also been reported as occurring without preeclampsia (10). Others suggested that there is a predisposition for the occurrence of preeclampsia and HELLP syndrome in early pregnancy (44).

As a result, there have been several debates and speculations about the existence of HELLP syndrome as a separate disease entity or an integral part of preeclampsia (45). The source of the debate is that since the pathophysiology of vascular injury is common for both, all the criteria used to diagnose the HELLP syndrome can also be found in part or as a whole in women with preeclampsia-eclampsia. The presence of these manifestations in women with preeclampsiaeclampsia was also recognized long ago (42).

In the author's opinion, the debate should not only be about putting it as a separate disease entity or as a severe form of preeclampsia. From the outset, why do we need to give a separate name when the triad of laboratory derangements present (anemia, thrombocytopenia, elevated liver enzymes)? As described before, these are primarily clinical features of the vascular disorder in the hematologic and hepatic system. Furthermore, the elevated plasminogen activator inhibitor-1 (PAI-1), endothelial activation and damage are common characteristics and early phenomena in both preeclampsia and HELLP syndrome without preeclampsia $(10,46,47)$. The other symptoms regarded as manifestations of HELLP syndrome (malaise, epigastric pain, nausea, vomiting, and weakness) (48) are nonspecific and some are also manifestations of anemia and preeclampsia (9). Other authors also hypothesized an inborn error of the fatty acid oxidative metabolism for the etiopathogenesis of HELLP syndrome (10), but this could not be substantiated by other investigators.

Therefore, the author's opinion is not to put the HELLP syndrome aside or to maintain it as severe complication of preeclampsia-eclampsia; it is to describe the disease with the original problems (anemia, thrombocytopenia, elevated liver enzymes) as clinical manifestations of VDP.

\section{The majority of women diagnosed as gestational hypertension will ultimately be diagnosed as preeclamptic:}

Although several authors use gestational hypertension and preeclampsia interchangeably, the World Health Organization and ACOG put a distinction between the two $(3,6)$. However, it is noted that many women diagnosed as gestational hypertension actually have preeclampsia even before the development of proteinuria or any other organ manifestation. This may also be a sign of future chronic hypertension (6). Recently, one author suggests a new classification: preeclampsia superimposed on gestational hypertension as in the case of preeclampsia superimposed on chronic hypertension (49).

In conclusion, the time has come for a simple and uniform classification scheme. Chronic hypertension can be entertained like any other 
medical disorders during pregnancy. None of the currently used terminologies to describe this disease spectrum is inclusive or accurate. The disease process is not primarily a hypertensive disorder, but it rather is a vascular disorder of pregnancy (VDP) of unknown etiology. All systemic complications result from the microangiopathy (endothelial damage and vasospasm), with variable severity and onset. The systemic manifestations of VDP (convulsion, anemia, thrombocytopenia, hepatic dysfunction, acute renal failure, pulmonary edema, and hypertension) are self-explanatory and can be used to describe the severity of the disease via a simple, uniform classification scheme [Table 1].

Table 1: Vascular disorder of pregnancy (VDP) classification, and the place of antihypertensive and anticonvulsant administration

\begin{tabular}{|c|c|c|c|}
\hline $\begin{array}{l}\text { VDP- } \\
\text { disease } \\
\text { severity }\end{array}$ & Description & $\begin{array}{l}\text { Antihypertensive } \\
\text { and/or } \\
\text { anticonvulsant } \\
\text { indication }\end{array}$ & $\begin{array}{l}\text { Expectant } \\
\text { termination } \\
\text { pregnancy }\end{array}$ \\
\hline Class 0 & $\begin{array}{l}\text { Asymptomatic, blood pressure } \\
\text { <140/90mmHg, no evidence of } \\
\text { dysfunction }\end{array}$ & None & Expectant \\
\hline Class 1 & $\begin{array}{l}\text { Asymptomatic, systolic BP } 140-159 \text { and } \\
\text { diastolic 90-109 } \mathrm{mmHg} \text {, no evidence of } \\
\text { organs dysfunction }\end{array}$ & $\begin{array}{l}\text { Only magnesium } \\
\text { sulfate }\end{array}$ & $\begin{array}{l}\text { Expectant for < } 37 \\
\text { weeks gestation }\end{array}$ \\
\hline Class 2 & $\begin{array}{l}\text { Headache, epigastric pain, blurred vision or } \\
\text { vomiting but no evidence of organs } \\
\text { dysfunction. }\end{array}$ & magnesium & $\begin{array}{l}\text { Expectant for }<37 \\
\text { weeks unless the } \\
\text { symptoms persist or } \\
\text { worsen }\end{array}$ \\
\hline Class 3 & $\begin{array}{l}\mathrm{BP}>=160 / 110 \mathrm{mmHg} \text { or twice elevated liver } \\
\text { enzymes or creatinine value }>1.1 \mathrm{mg} / \mathrm{dl} \text { or } \\
\text { anuria or thrombocytopenia }<100,000 / \mathrm{mm} 3 \text {, } \\
\text { or hemolytic anemia }(\mathrm{Hb}<8 \mathrm{gm} / \mathrm{dl}) \text { or poor } \\
\text { biophysical profile or severe fetal growth } \\
\text { restriction. }\end{array}$ & $\begin{array}{l}\text { Antihypertensive }+ \\
\text { Magnesium sulfate }\end{array}$ & $\begin{array}{l}\text { Termination. } \\
\text { Buy time for steroid } \\
\text { if the GA }<34 \text { weeks } \\
\text { and hypertension is } \\
\text { controllable }\end{array}$ \\
\hline Class 4 & $\begin{array}{l}\text { Convulsion/cortical blindness/stroke or } \\
\text { pulmonary edema or cardiac failure or liver } \\
\text { hematoma/rupture or severe renal failure } \\
\text { (creatinine }>=5 \mathrm{mg} / \mathrm{dl} \text { ) or DIC or placental } \\
\text { abruption. }\end{array}$ & $\begin{array}{l}\text { Magnesium sulfate } \pm \\
\text { Antihypertensive }\end{array}$ & $\begin{array}{l}\text { Immediate } \\
\text { Termination }\end{array}$ \\
\hline
\end{tabular}

1. Class 0 is suggested taking into consideration the occurrence of convulsion among several asymptomatic and normotensive pregnant women for whom we may not do anything till a noble biomarker or neurosignal is identified.

2. In class IV, antihypertensive is optional for similar reason (occurrence of any of the listed complications with mild to moderate hypertension or without hypertension).

3. Magnesium sulfate is recommended for all with the exception of class 0 because of large body of data showing the occurrence of convulsion in several women with mild to moderate hypertension.

4. The simplified but comprehensive terminology (VDP) is also an advantage to avoid confusions with multiple and inconclusive terminologies in the formal education and training of health care workers. 
The main advantages of the current recommendation (VDP):

1. Since the vascular disorder is central and common for all the clinical manifestations, VDP avoids confusion surrounding a misperception that there is a natural, linear progression of disease and avoids missing atypical presentations. VDP also avoids the different terminologies not consistently and conclusively used across the globe.

2. Criteria to diagnose VDP will be based on one or more of the secondary effects like hypertension, neurologic manifestations (headache, blurred vision, visual loss, convulsion, stroke, vomiting), hepatic manifestations (epigastric pain, vomiting, elevated enzymes and bilirubin, subcapsular hematoma/rupture), renal manifestations (oliguria, elevated creatinine, BUN, uric acid), hematologic manifestations (thrombocytopenia, hemolytic anemia, elevated bilirubin and $\mathrm{LDH}$ ), ascites, independent edema, and evidences of uteroplacental insufficiency (poor biophysical profile, growth restriction, placental abruption). These symptoms would not be grouped to give another terminology and create confusion. Therefore, the diagnosis will be VDP with one or more of the above specific manifestations.

3. Once the diagnosis of VDP is made, differential treatment can be instituted to reflect the severity (Class) of the disease. This will have a big advantage not to miss the potentially complicating cases. In other words, several unforeseen complications (like convulsion) encountered in women diagnosed as mild preeclampsia can be avoided with early initiation of anticonvulsants. However, it has been noted above that in some women convulsion can be the first symptom and thus may not be totally avoidable.

4. The simplified but comprehensive terminology (VDP) is also an advantage to avoid confusions with multiple and inconclusive terminologies in the formal education and training of health care workers.

For management purpose, the severity of the VDP is classified and treatment modalities are suggested as presented in Table 1. Detail description of mode of delivery, antihypertensive and anticonvulsant drugs is beyond the scope of this manuscript. Lastly, the author would like to let the readers know that the suggested terminology and treatment options are open for discussion and further enrichment. 


\section{REFERENCES}

1. Bell MJ. A Historical Overview of Preeclampsia-Eclampsia. A J Obstet Gynecol Neonatal Nurs, 2010; 39(5): 510-518.

2. Duncan IC. Pre-eclampsia, eclampsia and the thrombotic microangiopathic syndromes of pregnancy. South African Journal of radiology, 2005; 9-12. www.ajol.info/index.php/sajr/article/viewFile /34452/6380

3. World Health Organization (WHO). WHO recommendation for prevention of preeclamapsia and eclampsia. 2011. Geneva/Switzerland.www.who.int/reproducti vehealth/publications/maternal_perinatal_hea lth/

4. Rojas-Arias JL, Ortiz-López LD, OrduñaAparicio WJ, Quintero-Loaiza CA, AcuñaOsorio E, Franco-Hernández A, ParraSaavedra M, Molina-Giraldo S, Figueras F. Characterization of Atypical Preeclampsia. Fetal Diagn Ther, 2015. (DOI:10.1159/000369553) [Epub ahead of print].

5. Sibai BM. Diagnosis, Prevention, and Management of Eclampsia. Obstet Gynecol, 2005; 105:402-10.

6. The American College of Obstetricians and Gynecologists (ACOG). Hypertension in pregnancy 2013. http://www.acog.org/Resources_And_Public ations/

7. Vigil-De Gracia P. Maternal deaths due to eclampsia and HELLP syndrome. Int $\mathbf{J}$ Gynaecol Obstet, 2009; 104(2):90-4.

8. Berhan Y, Berhan A. Should magnesium sulphate be administered to women with mild preeclampsia? A systematic review of literature on eclampsia. J Obstet Gynaecol Res, 2015; doi:10.1111/jog.12697 [Epub ahead of print].

9. Katz VL, Farmer R, Kuller JA. Preeclampsia into eclampsia: toward a new paradigm. Am J Obstet Gynecol, 2000; 182(6):1389-96.

10. Mihu D, Costin N, Mihu CM, Seicean A, Ciortea R. HELLP syndrome - a multisystemic disorder. J Gastrointestin Liver Dis, 2007; 16(4):419-24.
11. Chhabra S, Tyagi S, Bhavani M, Gosawi M. Late postpartum eclampsia. J Obstet Gynaecol, 2012; 32(3):264-6.

12. Bellamy L, Casas JP, Hingorani AD, et al. Pre-eclampsia and risk of cardiovascular disease and cancer in later life: systematic review and meta-analysis. BMJ, 2007; 335(7627):974.

13. Harskamp RE, Zeeman GG. Preeclampsia: at risk for remote cardiovascular disease. Am J Med Sci. 2007; 334(4):291-5.

14. Wikstrom A, Haglund B, Olovsson M, Lindeberg $\mathrm{S}$. The risk of maternal ischaemic heart disease after gestational hypertensive disease. BJOG, 2005; 112:1486-91.

15. Brown MA. Pre-eclampsia: a lifelong disorder. Med J Aust, 2003; 179:182-4.

16. Stekkinger E, Scholten R, van der Vlugt M, Van Dijk A, Janssen M, Spaanderman M. Metabolic syndrome and the risk for recurrent pre-eclampsia: a retrospective cohort study. BJOG, 2013; 120:979-986.

17. Bonora E. The metabolic syndrome and cardiovascular disease. Ann Med. 2006;38:64-80.

18. Wilson PW, D'Agostino RB, Parise $H$, Sullivan L, Meigs JB. Metabolic syndrome as a precursor of cardiovascular disease and type 2 diabetes mellitus. Circulation, 2005; 112:3066-72.

19. Lee AJ, Hiscock RJ, Wein P, Walker SP, Permezel M. Gestational diabetes mellitus: clinical predictors and long-term risk of developing type 2 diabetes: a retrospective cohort study using survival analysis. Diabetes Care, 2007; 30(4):878-83.

20. Vigorito C, Giordano A, Ferraro P. Hemodynamic effects of magnesium sulphate on the normal human heart. Am J Cardiol, 1990; 65: 709-12.

21. Tukur J. The use of magnesium sulphate for the treatment of severe preeclampsia and eclampsia. Ann Afri Medi, 2009; 8(2):76-80.

22. Subhankar Dasgupta, Debdutta Ghosh, Subrata Lall Seal, Gourisankar Kamilya, Madan Karmakar and Debdas Saha. Randomized controlled study comparing effect of magnesium sulfate with placebo on fetal umbilical artery and middle cerebral artery blood flow in mild preeclampsia at_34 
weeks gestational age. J Obstet Gynaecol Res, 2012; 38(5):763-771.

23. Al-Safi Z, Imudia AN, Filetti LC, Hobson DT, Bahado-Singh RO, Awonuga AO. Delayed postpartum preeclampsia and eclampsia: demographics, clinical course, and complications. Obstet Gynecol, 2011; 118(5):1102-7.

24. Blaauw J, Graaff R, van Pampus MG, van Doormaal JJ, Smit AJ, Rakhorst G, et al. Abnormal endothelium-dependent microvascular reactivity in recently preeclamptic women. Obstet Gynecol, 2005; 105:626-32.

25. Goulopoulou S, Davidge ST. Molecular mechanisms of maternal vascular dysfunction in preeclampsia. Trends Mol Med, 2015; 21(2):88-97.

26. Abalos E, Duley L, Steyn DW. Antihypertensive drug therapy for mild to moderate hypertension during pregnancy. Cochrane Database Syst Rev, 2014; 2:CD002252. doi: 10.1002/14651858.CD002252.pub3.

27. Ananth CV, Basso O. Impact of PregnancyInduced Hypertension on Stillbirth and Neonatal Mortality in First and Higher Order Births: A Population-based Study. Epidemiology, 2010; 21(1): 118-123.

28. Furuya M, Ishida J, Aoki I, Fukamizu A. Pathophysiology of placentation abnormalities in pregnancy-induced hypertension. Vasc Health Risk Manag, 2008; 4(6):1301-13.

29. Khalil A, Jauniaux E, Harrington K. Antihypertensive therapy and central hemodynamics in women with hypertensive disorders in pregnancy. Obstet Gynecol, 2009; 113(3):646-54.

30. Mutter WP, Karumanchi SA. Molecular mechanisms of preeclampsia. Microvasc Res, 2008; 75(1): 1-8.

31. Lamarca B. The role of immune activation in contributing to vascular dysfunction and the pathophysiology of hypertension during preeclampsia. Minerva Ginecol, 2010; 62(2):105-20.

32. Guller S, Ma YY, Fu HH, Krikun G, Abrahams VM, Mor G. The placental syncytium and the pathophysiology of preeclampsia and intrauterine growth restriction: a novel assay to assess syncytial protein expression. Ann N Y Acad Sci, 2008; 1127:129-33.

33. Pennington KA, Schlitt JM, Jackson DL, Schulz LC, Schust DJ. Preeclampsia: multiple approaches for a multifactorial disease. Dis Model Mech, 2012; 5(1):9-18.

34. Friedman SA, Schiff E, Emeis JJ, et al. Biochemical corroboration of endothelial involvement in severe preeclampsia. Am $J$ Obstet Gynecol, 1995; 172(1 Pt 1):202-3.

35. Taylor RN, de Groot CJ, Cho YK, et al. Circulating factors as markers and mediators of endothelial cell dysfunction in preeclampsia. Semin Reprod Endocrinol, 1998; 16(1):17-31.

36. Stella CL, Malik KM, Sibai BM. HELLP syndrome: an atypical presentation. Am J Obstet Gynecol, 2008; 198(5):e6-8.

37. Mattar F, Sibai BM. Eclampsia. VIII. Risk factors for maternal morbidity. Am J Obstet Gynecol, 2000; 182(2):307-12.

38. Douglas K A, Redman CWG. Eclampsia in the United Kingdom. BMJ, 1994;309:1395

39. Sibai BM, Abdella TN, Spinnato JA, Anderson GD. Eclampsia. V. The incidence of non-preventable eclampsia. Am J Obstet Gynecol, 1986; 154(3):581-6.

40. Lipstein H, Lee CC, Crupi RS. A current concept of eclampsia. Am J Emerg Med, 2003; 21(3):223-6.

41. Portis R, Jacobs MA, Skerman JH, Skerman EB. HELLP syndrome (hemolysis, elevated liver enzymes, and low platelets) pathophysiology and anesthetic considerations. AANA J, 1997; 65(1):37-47.

42. Sibai BM. The HELLP syndrome (hemolysis, elevated liver enzymes, and low platelets): much ado about nothing? Am J Obstet Gynecol, 1990; 162(2):311-6.

43. Sibai BM. Diagnosis, controversies, and management of the syndrome of hemolysis, elevated liver enzymes, and low platelet count. Obstet Gynecol, 2004; $103(5 \mathrm{Pt}$ 1):981-91.

44. Pawelec M, Karmowski A, Karmowski M, Krzemieniewska J, Kulczycka A, Gabryś MS, Koryś J, Gworys B. Inability to have children caused by recurrent HELLP syndrome in early pregnancies - implications 
for a review of literature. Adv Clin Exp Med, 2013; 22(5):753-8.

45. Pritchard JA, Weisman R Jr, Ratnoff OD, Vosburgh GJ: Intravascular hemolysis, thrombocytopenia and other hematologic abnormalities associated with severe toxemia of pregnancy. N Engl J Med, 1954, 250:8998.

46. Landi B, Tranquilli AL. HELLP syndrome and placental inflammatory pathology. Minerva Ginecol, 2008; 60(5):389-98.

47. Abildgaard U, Heimdal K. Pathogenesis of the syndrome of hemolysis, elevated liver enzymes, and low platelet count (HELLP): a review. Eur J Obstet Gynecol Reprod Biol, 2013; 166(2):117-23.

48. Haram K, Mortensen JH, Nagy B. Genetic aspects of preeclampsia and the HELLP syndrome. J Pregnancy, 2014; 2014:910751. doi: 10.1155/2014/910751.

49. Adu-Bonsaffoh K. Proposed modification to classification of hypertensive disorders in pregnancy. XIXth World Congress for the Study of Hypertension in Pregnancy. Accessed in April 2015 from: http://www.sciencedirect.com/science/article/ pii/S2210778914003419. 